\title{
Use of orcein in detecting hepatitis B antigen in paraffin sections of liver
}

\author{
P KIRKPATRICK
}

From the Department of Histopathology, John Radcliffe Hospital, Headington, Oxford OX3 9DU

SUMmaRY This study has shown that different supplies/batches of orcein perform differently and may fail. The "natural" forms generally performed better although the most informative results were obtained with a "synthetic" product. Orcein dye solutions can be used soon after preparation and for up to 7 days without the need for differentiation. After 10 days or so the staining properties become much less selective. Non-specific staining severely reduces contrast and upon differentiation overall contrast is reduced and the staining of elastin is reduced. Copper-associated protein positivity gradually fails and after 14 days is lost.

For demonstrating HBsAg in paraffin sections of liver, it is best to use orcein dye preparations that are no older than 7 days and to test each batch of orcein against a known positive control.

Orcein dye solutions are now commonly used for the detection of hepatitis B surface antigen (HBsAg) and copper-associated protein in paraffin sections of liver. ${ }^{1}$ It is generally believed that orcein dyes from a single source should be used. ${ }^{2-6}$ Variable results are obtained with different reagents perhaps because of different manufacturing procedures or significant batch variations.

This paper evaluates the ability of several commonly available orcein dyes to stain HBsAg and copper-associated protein in hepatocytes. It demonstrates not only that orcein batches differ in their ability to stain both of these components but that any given orcein solution deteriorates with time so that it loses its capacity to distinguish the structures under study from the background. This is an important point as there have been conflicting reports as to the effect of age on orcein solutions used for HBsAg demonstration. ${ }^{3} 7$

\section{Material and methods}

Material from one formalin-fixed liver wedge biopsy was used throughout this study. This liver was shown to contain HBsAg using immunoperoxidase methods $; 8$ in addition, the patient's serum contained $\mathrm{HBsAg}$ in high titre. Sections $(4 \mu \mathrm{m})$ were prepared from this routinely processed paraffin-embedded liver wedge each time staining

Accepted for publication 27 July 1981 was evaluated.

Eight samples of orcein were supplied by: Sigma London Chemical ("natural" batch Nos 89C-0264 and 59C-0254 and "synthetic" batch Nos 31F-0441); Raymond A Lamb ("natural" batch No 5094); Difco Laboratories ("natural" batch No 3220); BDH Chemicals ("synthetic" batch No 5575420A); Clin-Tech ("natural" batch No 2106); Hopkin and Williams (Gurr Products) ("synthetic" batch No 14018).

Each orcein preparation was dissolved to a concentration of $1 \%(w t / w t)$ in $70 \%$ ethanol and adjusted to $\mathrm{pH} 1-2$ with concentrated $\mathrm{HCl}$. Orcein staining was performed by treating dewaxed and hydrated sections as follows: acidified potassium permanganate $(50 \mathrm{ml} 0.5 \%$ aqueous $+2.5 \mathrm{ml} \mathrm{3 \%}$ $\mathrm{H}_{2} \mathrm{SO}_{4}$ ) for $10 \mathrm{~min} ; 2 \%$ aqueous oxalic acid for $10 \mathrm{~min}$; washed in tap water; stained with orcein for $2 \mathrm{~h}$ at $22^{\circ} \mathrm{C}$; washed briefly in tap water; rinsed in $70 \%$ alcohol; dehydrated, cleared and mounted in DPX. Evaluation of the staining properties of each orcein batch was made at various intervals after the solutions were made from zero time to 28 days. Only one staining bath of each dye supplied was prepared and these baths were then used for all the evaluations (Table).

It was apparent that after 14 days in solution all of the orcein batches required some differentiation (Figs 1 and 2). This was achieved using $1 \%$ hydrochloric acid in $70 \%$ alcohol for five seconds after exposure to orcein. For this reason a duplicate set of slides was included at both the 14-day and 28-day 
Table 1 Orcein staining of HBsAg and copper-associated protein (CAP) in paraffin sections of liver

\begin{tabular}{|c|c|c|c|c|c|c|c|c|}
\hline \multirow[t]{2}{*}{ *Orcein supply } & \multirow[t]{2}{*}{ Reaction } & \multicolumn{7}{|c|}{ Age (days) of orcein solution } \\
\hline & & 0 & 2 & 7 & 14 & $14+d i f f$ & 28 & $28+$ diff \\
\hline \multirow[t]{3}{*}{ 1. Natural } & $\begin{array}{l}\text { HBsAg } \\
\text { CAP }\end{array}$ & $t+$ & ++ & +++ & +++ & ++ & ++ & + \\
\hline & $\begin{array}{l}\text { CAP } \\
\text { Elastin }\end{array}$ & $\begin{array}{l}+ \\
+\end{array}$ & $\begin{array}{l}+ \\
+\end{array}$ & $\begin{array}{l}+ \\
+\end{array}$ & + & + & $\bar{t}-$ & $\bar{t}-$ \\
\hline & Non-specific & - & - & +- & + & +- & + & +- \\
\hline \multirow[t]{4}{*}{ 2. Natural } & HBsAg & - & - & - & - & - & - & - \\
\hline & CAP & - & - & - & - & - & - & - \\
\hline & Elastin & - & - & - & - & - & - & - \\
\hline & Non-specific & +- & +- & +- & +- & +- & +- & +- \\
\hline \multirow[t]{3}{*}{ 3. Natural } & HBsAg & $t+t$ & +++ & +++ & $++t$ & ++ & ++ & + \\
\hline & $\begin{array}{l}\text { CAP } \\
\text { Elastin }\end{array}$ & $\begin{array}{l}+ \\
+\end{array}$ & $\begin{array}{l}+ \\
+\end{array}$ & $\stackrel{+}{+}$ & $\begin{array}{l}+ \\
+\end{array}$ & $\begin{array}{l}+ \\
+-\end{array}$ & $\bar{t}$ & $\bar{t}-$ \\
\hline & Non-specific & - & - & +-- & +- & +-- & +- & +-- \\
\hline \multirow[t]{4}{*}{ 4. Natural } & HBsAg & + & + & + & + & + & + & + \\
\hline & CAP & + & ++ & ++ & + & +- & - & - \\
\hline & Elastin & +- & +- & +- & +- & +- & + & +- \\
\hline & Non-specific & - & - & +- & +- & +- & + & +-- \\
\hline \multirow[t]{4}{*}{ 5. Natural } & HBsAg & - & - & +-- & - & - & - & - \\
\hline & CAP & - & - & - & - & - & - & - \\
\hline & Elastin & - & - & - & - & - & - & - \\
\hline & Non-specific & +- & +- & +- & +- & +- & +- & +- \\
\hline \multirow[t]{4}{*}{ 6. Synthetic } & HBsAg & + & + & + & + & +- & + & +- \\
\hline & CAP & +- & +- & +- & +- & +- & - & - \\
\hline & Elastin & + & + & +- & +- & +- & + & +- \\
\hline & Non-specific & +- & +- & +- & + & +- & ++ & +- \\
\hline \multirow[t]{4}{*}{ 7. Synthetic } & HBsAg & + & + & + & + & +- & + & +- \\
\hline & CAP & + & +- & + & +- & +- & - & - \\
\hline & Elastin & + & + & + & + & +- & + & +- \\
\hline & Non-specific & + & +- & +- & + & +- & + & +-- \\
\hline \multirow[t]{4}{*}{ 8. Synthetic } & HBsAg & $++t$ & +++ & +++ & +++ & ++ & ++ & + \\
\hline & CAP & ++ & ++ & ++ & & + & +-- & - \\
\hline & Elastin & + & + & + & + & +- & + & +- \\
\hline & Non-specific & - & - & +- & +- & +-- & +- & +-- \\
\hline
\end{tabular}

* Suppliers are not identified.

$+\rightarrow+++=$ increasing positivity.

$+-\rightarrow+--=$ decreasing positivity.

$\operatorname{diff}^{-}=$differentiation.

evaluations in order to assess the effects of differentiation.

\section{Results}

The relative merits of each dye were assessed by reference to the following criteria: HBsAg positivity; presence and intensity of background staining; staining of copper-associated protein; staining of elastin.

The intensity of staining reactions are graded according to the scale shown in the footnote to the Table. Rather than mention the source of each orcein, each batch of orcein is given a code number in this Table.

\section{Discussion}

The results obtained indicate that there were distinct differences between the staining properties of the dye samples. One "synthetic" sample gave very good results revealing much granular detail in the HBsAgpositive cells and demonstrating copper-associated protein particularly distinctly (Fig. 3). Two of the "natural" samples also gave very good results which were consistent, but two of the "natural" samples failed to demonstrate HBsAg-positive cells at all.

This pattern of reaction continued until the evaluation at 14 days, when all the positive staining dye solutions began to stain normal hepatocytes. Therefore, it became difficult to distinguish between HBsAg and copper-associated protein "containing" hepatocytes and normal hepatocytes.

At the 14-day evaluation it became apparent that all the positive-staining solutions required some differentiation. This was achieved using a standard time necessary to reduce the background to an acceptable level. Even after differentiation at 14 days the results were not as satisfactory as at the fresh, 2 and 7 days. Contrast was reduced between positive cells and the background, copper-associated protein positivity was gradually lost and elastin staining was reduced with differentiation. At the 28-day evaluation these changes were so marked that the study was discontinued.

There may be many reasons why these differences 


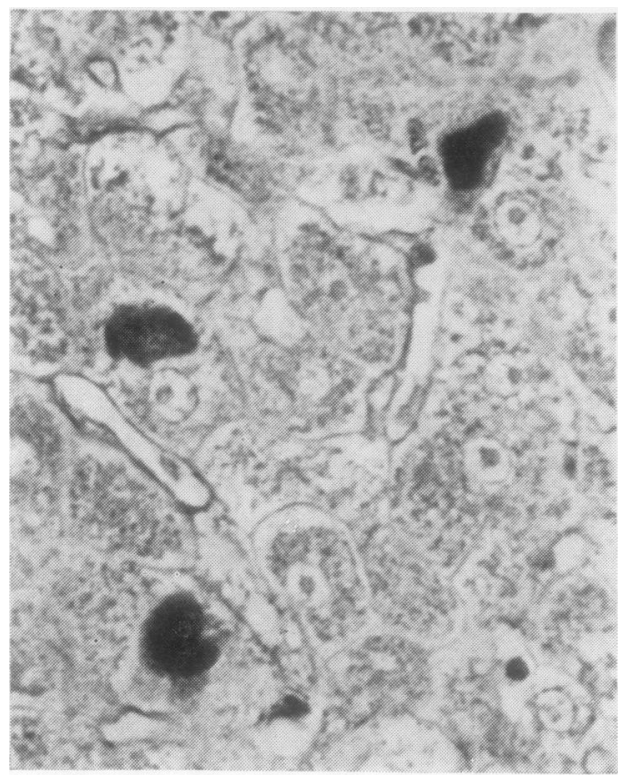

Fig. 1 HBsAg-positive liver stained with orcein sample 3 at the 14-day stage. This sample gave less non-specific staining than some other samples but normal hepatocytes are gradually beginning to stain. $\times 400$

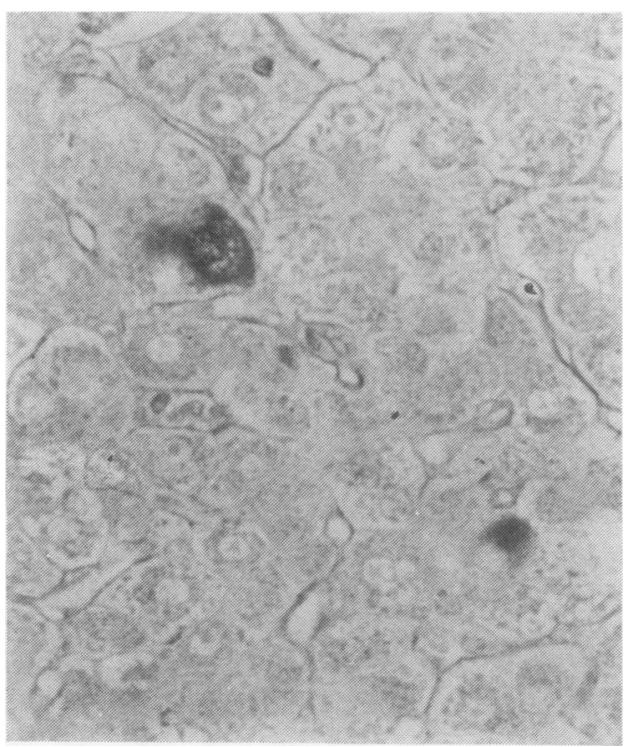

Fig. 2 As in Fig. 1 but after minimum differentiation. The contrast between positive cells and normal cells is decreased. $\times 400$

in staining properties occur; orcein is supplied as either "natural"' or "synthetic" and is traditionally produced in the "natural" form. This is achieved

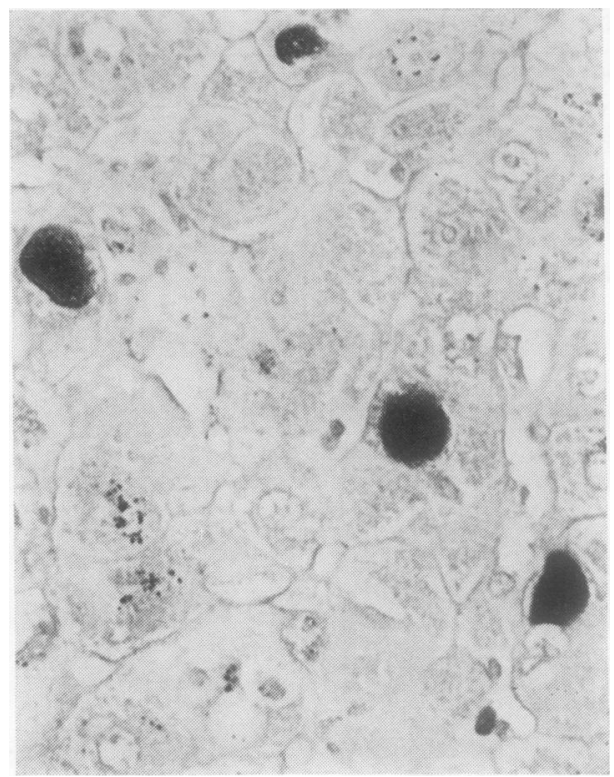

Fig. 3 Optimum results obtained with sample 8 at the 7-day stage. Good contrast, HBs Ag-positive cell detail and well demonstrated CAP is shown. $\times 400$

by the action of ammonia and air on lichens (information supplied by Sigma Chemical Co, London), converting orcinol into orcein. "Synthetic" orcein can be produced by the same procedure using synthetically derived orcinol. There seems to be no clear indication that one form of orcein was superior to another.

It has been suggested ${ }^{10}$ that some types of orcein require increased concentrations of orcein and $\mathrm{HCl}$ and this approach may be of value in trying to improve the performance of a given dye sample.

It is, however, recommended that a laboratory should consider whether the orcein in use is in fact the best available for HBsAg demonstration. It is not suggested that orcein from one particular supplier can be guaranteed for use in $\mathrm{HBsAg}$ demonstration, indeed both the most and least effective samples in this study were obtained from the same supplier.

The method used in this paper offers the simplest use of this technique which can give excellent results which are reproducible in a routine environment where relatively inexperienced staff are often required to perform such methods.

I am grateful to Professor JO'D McGee and Mr AJ Chaplin, for their help, and the following companies for providing the orcein samples and relevant information: Raymond A Lamb; Difco Labora- 
tories; BDH Chemicals; Clin-Tech Limited; Sigma London Chemical Company; Hopkin \& Williams (Gurr Products). I am grateful to Mrs D Smith for typing the manuscript.

\section{References}

${ }^{1}$ Shikata T, Uzawa T, Yoshiwara N, Akatsuka T, Yamazaki S. Staining methods of Australia antigen in paraffin section-detection of cytoplasmic inclusion bodies. Jpn J Exp Med 1974;44:25-36.

${ }^{2}$ Sumithran E. Methods for detection of hepatitis B surface antigen in paraffin sections of liver: a guideline for their use. J Clin Pathol 1977;30:460-3.

${ }^{3}$ Fredenburgh JL, Edgerton SM, Parke AE. A modification of the aldehyde fuchsin and orcein stains for hepatitis B surface antigen in tissue and a proposed chemical mechanism. Journal of Histotechnology 1978;1:6.

${ }^{4}$ Clausen PP, Thomsen P. Demonstration of $\mathrm{HBsAg}$ in liver biopsies. Acta Pathol Microbiol Scand (A) 1978; 86:383.

5 Portmann B, Galbraith RM, Eddleston ALWF, Zuckerman $A J$, Williams R. Detection of $\mathrm{HBsAg}$ in fixed liver tissue-use of a modified immunofluorescent technique and comparison with histochemical methods. Gut 1976;17:1-9.

${ }^{6}$ Sipponen P, Salaspuro MP, Makkonen HM. Orceinpositive hepatocellular material in the histological diagnosis of primary biliary cirrhosis. Ann Clin Res 1975;7:273-7.

7 Thomsen P, Poulsen H, Peterson P. Different types of ground glass hepatocytes in human liver biopsiesmorphology, occurrence and diagnostic significance. Scand J Gastroenterol 1976;11:113-9.

${ }^{8}$ Burns J. Immunoperoxidase localisation of hepatitis B antigen (HB) in formalin-paraffin processed liver tissue. Histochemistry 1975;44:133-5.

${ }^{9}$ Stecher PG, ed. Merck Index. 8th ed. Rahway, New Jersey: Merck and Co, 1968.

${ }^{10}$ Scheuer PJ. Liver biopsy interpretation. 3rd ed. London: Bailliere Tindall, 1980.

Requests for reprints to: Mr P Kirkpatrick, Department of Histopathology, Level 1, John Radcliffe Hospital, Headington, Oxford OX3 9DU, England. 